\title{
Phenotypic plasticity of an invasive weed Ambrosia artemisiifolia L. in agrobiocenoses of the South of Russia
}

\author{
Leonid Esipenko ", Aleksandr Podvarko, and Anatoliy Savva \\ All-Russian Institute of Biological Plant Protection Krasnodar-39, 350039, Russia
}

\begin{abstract}
Invasive weeds are characterized by high phenotypic plasticity, which allows them to adapt to new climatic conditions due to variable phenotypes that have arisen in the historical time scale under the control of natural selection. Colonization of such plants takes place locally in accessible anthropogenic cenoses. In the South of Russia the most typical invasive plant is Ambrosia artemosiifolia $\mathrm{L}$. We We examined the discrete variation by vegetative feature - shoot length according to 12 genotypes of ragweed in agrocenoses of Krasnodar Krai.
\end{abstract}

\section{Introduction}

In different environments, one genotype can reflect different phenotypes. This phenomenon is known as phenotypic plasticity [1]. Adventive plants under new living conditions are affected by various adverse abiotic and biotic stress factors.

Ragweed is a classic invasive weed plant that populates anthropogenic landscapes due to its rapid adaptation to environmental factors. This process proceeds in the form of incoherent evolution due to epigenetic system rearrangements reinforced and fixed by natural selection for several generations. Such ecological plasticity allows not only ragweed, but also many other invasive species to invade a heterogeneous habitat $[2,3]$.

Obviously, in the new habitat there is an increase in phenotypic characteristics, some of which will disappear. As a rule, these are conditionally normal common phenes in the native habitat and the appearance of new phenoforms not previously encountered. The newly appeared phenoforms in places of acclimatization often reflect physiological and environmental changes, which can affect both the width and the narrowness of the reaction rate of an invasive weed plant [4].

Variability of ragweed includes habitus variation in size, weight and reproductive capacity, which contributes to its distribution due to the high plasticity of the reproductive organs [5]. At the same time, nowadays, there is only fragmentary information about phenotypic plasticity in the shoot length not only for ragweed, but also for other plants [6, 7].

The south-western arid regions of North America are considered the birthplace of ragweed [8]. In the Russian Federation, ragweed was introduced in 1918. It can be found between $30^{\circ}$ and $45^{\circ}$ north latitude, mostly occupying areas in the South of Russia, Northern Caucasus, Rostov and Volgograd regions, Kalmykia, Primorsky Krai.

"Corresponding author: esipenkol@yandex.ru 
Our experimental results revealed a high phenotypic plasticity of ragweed: high seed productivity, high allopathic properties, resistance to adverse abiotic factors, the development of resistance to various herbicides, which is confirmed by the studies of other researchers as well [9].

This research covers the patterns of phenotypic plasticity of ragweed in the shoot length.

\section{Materials and methods}

The studies were carried out Krasnodar Krai during several field seasons from 2017 to 2019. To study phenotypic plasticity, we selected two fields one of which was occupied by sunflower crop and the other by corn crop. On the selected agrocenosis, 25 ragweed plants with 12 genotypes were selected: genotypes 1-4 belong to long morphology (group A), genotypes 5-8 to medium one (Group B), genotypes 9-12 to short morphology (group C). Starting from the budding phase, the total length of all branches was measured once every ten days during one month. Vegetative growth was estimated by subtracting the initial shoot length from the total final length. The average values of each trait from an individual plant were used for statistical analysis. Data processing was carried out in Excel program.

\section{Results and discussion}

The environment can cause changes in plant behavior at a morphological or physiological level. Such changes are crucial for the survival of invasive weeds under heterogeneous and variable conditions $[10,11]$. The periods of plants development can be flexible, and many phenotypic reactions to environmental stress factors can be the result of a decrease in shoot length $[12,13]$.

Vegetative traits, such as shoot length, in ragweed vary depending on the type of agrocenosis and its genotype. The ragweed shoot length in the sunflower crop was longer than in the corn crop in all genotypes and this shows the effect of the habitat on the plant (Fig. 1). To control ragweed, agrotechnical techniques and modern herbicidal preparations containing DV glyphosate, glufosinate, imazamox, tribenuron-methyl, etc. are used. The use of a complex of exterminatory measures does not effect positively due to ragweed morphophysiological features of ontogenesis. The use of herbicides on sunflower crop against ragweed leads to inhibition of the cultivated plants. Recently, discrete variations of the traits have been noted, that contribute to the development of ragweed resistance to herbicides [14].

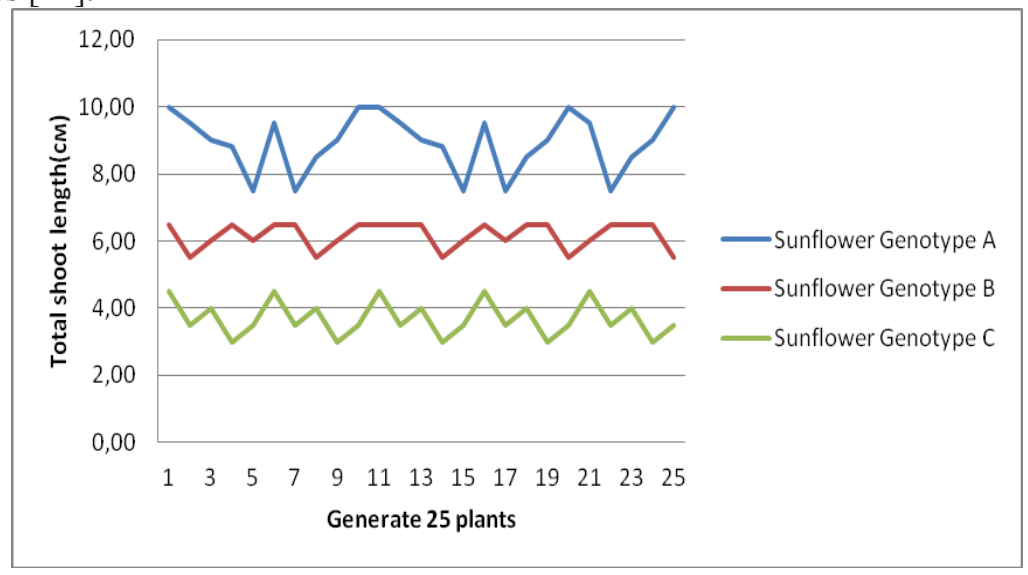

Fig.1. Phenotypic plasticity of ragweed in sunflower crop agrocenosis 
In corn agrocenosis, the use of herbicides makes it possible to effectively carry out exterminatory measures against A.artemisiifolia and associated weeds. Such chemical pressure affects the shoot length (Fig. 2).

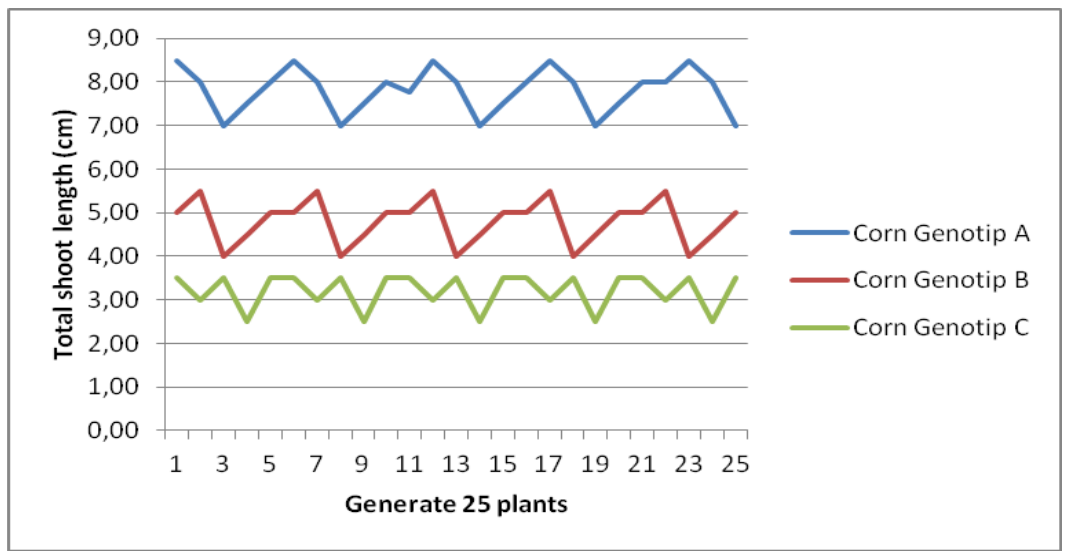

Fig. 2. Phenotypic plasticity of ragweed in corn crop agrocenosis

Ragweed resistance to herbicides is due to its modular organization. The presence of the apical meristem in the axils of the leaves, due to which lateral shoots (modules) develop, promotes the formation of similar structural elements that serve as the basis of modular growth.

The most vulnerable period of the growth and development of ragweed is the phase of 3-4 true leaves, during this period it forms up to 4 leaves with a shoot module length of 3 to $12 \mathrm{~cm}$. The processes of intensive growth resist the unfavorable conditions due to the multivariance of ontogenesis in ragweed.

In the budding phase, the number of leaves formed on the central shoot varies from 7 to 13 leaves, the shoot length of the module is within $30-52 \mathrm{~cm}$. At this stage of ontogenesis, the invader reaches the highest biomass and resists all environmental changes, including the effect of chemical compounds . Deviations in development happened in the first period of development "come back to normal." Destruction of the leaf surface mechanically or partially chemically does not affect its development, the vegetative mass is restored. In this phase, ragweed shows signs typical for 12 genotypes.

The obtained results show the correlation between ragweed genotypes and cultivated crops in agrocenosis. There are no interactions between A, B and C genotypes when they grow together in agrocenoses of different crops (Fig. 1, 2). In such a situation, the ragweed genotypes will not be able to prevent the elimination of a particular combined genotype, at the same time, they clearly interact within the group and there is no genetic difference and thereby participate in natural selection [15]. The ecological flexibility of the invasive plant contributes to the occupation of new territories due to phenotypic plasticity in contrasting climatic zones. Ragweed in colonization zones retains its genetic structure in heterogeneous environments, and the complex of genotypes allows it to interact with the new environment and successfully acclimatize.

\section{Conclusions}

Discrete variations of $A$. artemisiifolia traits are a characteristic feature of this invasive weed, that contribute to the ability to colonize and maintain its population genetic structure in adventitious agrocenoses. The obtained results can be used to predict the development of 
ragweed resistance to one or another herbicide. Further research will also allow us to study the adaptive nature of the mechanism of its phenotypic plasticity to develop a strategy for the management of ragweed.

The research was carried out in accordance with the state task No 075-00376-19-00 of Ministry of Science and Higher Education of the Russian Federation as part of a study on topic No 0686-2019- 0010 and partly with the support of the FSBI "RFBR".

\section{References}

1. S. Matesanz, E. Gianoli, and F. Valladares, Annals of the New York Academy of Sciences, 1206, 35-55 (2010) https://doi.org/10.1111/j.1749-6632.2010.05704.X

2 . M. Zunzunegui, M. C. D. Barradas, F. Ain-Lhout, L. Alvarez Cansino, M. P. Esquivias, F. G. Novo, PlantEcology, 212(1), 127-142. (2011) https://doi.org/10.1007/s11258-010-9809-7

3. L. Gratani, R. Catoni, G. Pirone, A. R. Frattaroli, L. Varone, Photosynthetica, 50 (1), 15-23. (2012) https://doi.org/10.1007/s11099-012-0006-X

4. A. Bonito, L. Varone, and L. Gratani, Photosynthetica, 49(1), 75-86. (2011) https://doi.org/10.1007/s11099-011-0014-2

5. M.A. Molina-Montenegro, J.Pẽnuelas, S. Munn'e-Bosch, J. Sardans, Biological Invasions, 14 (1), 21-33. (2012). https://doi.org/10.1007/ s10530-011-0055-2

7. M. E. Dorken, S. C. H. Barrett, Journal of Ecology, 92, 32-44. (2004) http://doi/10.1111/j.1365-2745.2004.00857.x

8. U. Niinemets, Ecological Research, 25(4), 693-714. (2010) http://doi/10.1007/s11284-010-0712-4

9. B. Fumanal, C. Girod, G. Fried, F. Bretagnolle, B. Chauvel, Weed Res., 48, 349359. (2008) https://doi.org/10.1111/j.1365-3180.2008.00627.x

10. C., Gauvrit, B. Chauvel, Weed Research 5, 503-510. (2010) https://doi.org/10.1111/j.1365-3180.2010.00800.x

11. R. Catoni, L. Gratani, and L. Varone, Ecology of Plants, 207, 442-449. (2012) https://doi.org/10.1016/j.flora.2012.02.007

12. A. M. Davidson, M. Jennions, and A. B. Nicotra, Ecology Letters, 14(4), 419431. (2011) http://dx.doi.org/10.1111/j.1461-0248.2011.01596.x

12.Y.Vitasse, C.C. Bresson, A. Kremer, R. Michalet, S. Delzon, Functional Ecology, 24(6) 1211-1218. (2010) http://dx.doi.org/10.1111/j. 1365-2435. 2010.01748.

13. S.Richter, T. Kipfer, T. Wohlgemuth, C. C. Guerrero, J. Ghazoul, B. Moser,. Oecologia, 169(1), 269-279. (2012) http://dx.doi.org/10.1007/ s00442-011-2191-x

14. S.L. Rousonelos, R. M. Lee, M. S. Moreira, M. J. VanGessel, P. J. Tranel, Weed Science, 60(3). (2012) https://doi.org/10.1614/WS-D-11-00152.1

15. D.W. Pfennig., M.A. Wund, E.C. Snell-Rood, T. Cruickshank, C.D. Schlichting, A.P. Moczek, Trends Ecol. Evol., 25(8), 459-467. (2010) https://doi.org/10.1016/j.tree.2010.05.006 